\title{
Attachment Styles as Predictors of Substance Use Among Secondary School Students in Nairobi County, Kenya
}

\author{
Walter Odera Owino ${ }^{1}$ Jonathan Muema Mwania ${ }^{2 *}$ Newton Mukholwe Asakhulu $^{1}$ \\ 1. School of Education, Maasai Mara University, P.O Box 861, Narok, Kenya \\ 2. School of Education, Humanities and Social Sciences, South Eastern Kenya University, \\ P.O Box 170 - 90200, Kitui, Kenya \\ *Email: muemamwania@yahoo.com
}

\begin{abstract}
Substance use is common among secondary school students in Kenya and poses a threat to their health and academic achievement. Therefore, there is need to find out determinants of substance use so that measures can be taken to discourage it. Previous research has shown that attachment styles influence not only adolescents' adjustment but also their tendency to engage in deviant behaviors like substance use. This study investigated whether attachment styles predict substance use among secondary school students in Nairobi County. The study was based on the attachment theory and attachment security was conceptualized in terms of four attachment styles: secure, preoccupied, dismissing and fearful. A correlational design was adopted for the study. Data was collected using a self-administered questionnaire. The Attachment Styles Questionnaires was used to measure the four attachment styles and substance use was measured on an 11 item likert scale. The study targeted 10,451 Form Three students in 79 public secondary schools in Nairobi County. Three sub-counties were purposively selected and nine schools from the three sub-counties were selected using stratified random sampling. A sample of 385 students was randomly selected from the nine schools. Multiple linear regression analysis was used to test the hypothesis and determine the prediction of substance use by the attachment styles. The main finding of the study was that attachment styles predicted substance use among secondary school students $(\mathrm{F}=4.954, \mathrm{P}=.001)$ and accounted for $5.6 \%$ of the variance in substance use $\left(\mathrm{R}^{2}=0.56\right)$. Secure attachment style predicted less substance use $(\beta=-.117, \mathrm{P}=.028)$ whereas dismissing attachment style significantly predicted higher levels of substance use $(\beta=.174, \mathrm{P}=.004)$. The study recommended that guidance and counseling teachers take students' attachment styles into consideration when tackling substance use and encourage parents and guardians to foster more secure attachment with their children.
\end{abstract}

Keywords: Attachment styles, attachment anxiety, attachment avoidance, secure, preoccupied, dismissing, substance use

DOI: $10.7176 / \mathrm{JEP} / 12-30-11$

Publication date:October $31^{\text {st }} 2021$

\section{Introduction}

The high prevalence of substance use in adolescents is a matter of growing public health concern locally and internationally (Schulte \& Hser, 2014; Ondieki, 2017). Milin and Walker (2015) have observed that substance use has gained acceptability among adolescents and that increasingly younger adolescents are using alcohol, tobacco, marijuana and other drugs. They note how adolescence is the time when substance use disorders are most likely to take root. Jordan and Andersen (2017) explain that many people who end up with substance use disorders start using substances between the ages of 12 and 17. In regards to the Kenyan secondary school population, the National Authority for the Campaign Against Drug Abuse (NACADA, 2016) reports that early adolescence is the time when most secondary school students are at the highest risk of developing substances use habits. Brown and others (2008) point out the fact that adolescents have a tendency to experiment with novel and risky behaviors. They suggest that experimentation may be a normal part of maturation during adolescence. Nevertheless, the authors caution that prolonged or regular experimentation with alcohol and other substances may lead to serious consequences including substance use disorders.

Substance use in adolescence is associated with a host of problems. Mulvey, Schubert and Chassin (2010) highlight the fact that adolescents involved in serious offenses also tend to have problems with drugs and alcohol use. They further state that substance use at an early age predicts offending behavior at a later age. Substance use during adolescence is linked to violence (Kulak \& Griswold, 2019). Kamenderi and other authors (2019) point to 
the fact that use of drugs by students is a common factor in disturbances that have been witnessed in secondary schools in Kenya. Omboto, Ondiek, Odera and Oyugi (2013) have noted that substance use leads to violence, arson and school dropout among Kenyan secondary school students. A study that Kingendo (2015) carried out in secondary schools in Nairobi County showed that using substances was associated with bullying behavior. Substance use in adolescence is linked to risky sexual behavior. Adolescents from Finland, Scotland, France and Poland who reported using substances were significantly more likely to become sexually active before they turned 16 in one study (Madkour, Farhat, Halpern, Godeau \& Babhainn, 2010). Other health problems associated with substance use include depression, sleep disturbances, weight loss, suicidal tendencies and mental illness (Gore et al, 2011; Kisilu, Ayuya, Ndolo \& Mwavua, 2019). Copeland et al (2009) note that adolescents who start using substances at the age of 15 or earlier are particularly at risk of developing more problematic substance use disorders.

Moreover, substance use among school students is a matter of concern because experimentation with one substance often leads to experimentation with other more harmful ones. Milin and Walker (2015) point to the fact that most cocaine and heroin users started by using alcohol or smoking cigarettes. Thus, the more easily available and legal substances like alcohol and cigarettes may act as "gateways" to more dangerous illicit drugs. Kisilu et al (2019) note that in the early stages of substance use, the commonly used substances are alcohol, tobacco, inhalants and marijuana. Over time, users become more involved with marijuana and eventually use hard drugs. They explain how marijuana and khat are popular among the youth because they are affordable and are not thought of to be harmful. Health risk behaviors such as substance use that start during adolescence continue into adulthood and affect many aspects of a person's life (Gore et al, 2011).

Jumbe, Mwenda-kamninga, Mwalwimba and Kalu (2021) assert that the prevalence of substance use among young people in sub-Saharan Africa is so high that it has become a matter of public health concern. A recent systematic review of Sub-Saharan Africa found that $41.6 \%$ of adolescents admitted using at least one substance and the most widely used substances were alcohol (40.8\%) and tobacco (45.6\%) (Olawole-Isaac, Ogundipe, Amoo $\&$ Adeloye, 2018). In Kenya, NACADA (2012) has surveyed alcohol and other drug use patterns and arrived at the finding that the youth are the demographic group most affected by alcohol and other drugs. A study by Njoki (2013) found that $40 \%$ of secondary school students in Kiambu County in central Kenya had consumed alcohol, most of which was illegal home-made liquor. In the same study, 15\% of students had smoked cigarettes, $5 \%$ had smoked marijuana and $2 \%$ had used cocaine. Waithima (2017) found that $57.4 \%$ of secondary school students in her study had used tobacco, alcohol or other drugs in their lifetime. Alcohol was the most widely used by $48.6 \%$ followed by tobacco (31.1\%) and other drugs (37.8\%). The study found a current prevalence rate of substance use of $48.7 \%$ with alcohol consumption being most prevalent $(34.7 \%)$. In a survey of substance use in secondary schools, Ondieki (2017) found that alcohol was the most popular substance among secondary school students followed by cigarettes, marijuana, kuber and sniffing glue.

In Nairobi County, a survey by NACADA (2010) reported a high rate of alcohol consumption among students with $36.3 \%$ of them reporting lifetime use. The study also revealed high prevalence of khat (31.5\%), tobacco (20.2\%), marijuana (9.8\%) and other drugs (7.0\%). Studies by Abur (2014) and Owino (2017) also confirmed high rates of drinking, cigarette smoking and marijuana and other drug use among various segments of the youth population in Nairobi County. Kingendo (2015) underscored the rate of substance use in her study in which more than $80 \%$ of respondents said they had witnessed schoolmates using various substances. Given the high prevalence of alcohol and other substance use among adolescents and especially in Nairobi County and the associated dangers of this behavior, there is need to uncover predictors of such deviant behavior. Attachment security may influence secondary school students' involvement in deviant behavior and this study investigated whether students' attachment styles predicted substance use behavior.

\section{Objective of the Study}

The objective of the study was to find out whether attachment styles predicted substance use among secondary school students in Nairobi County.

\section{Hypothesis}

The hypothesis guiding the study was that there is no statistically significant relationship between attachment styles and substance use among students in Nairobi County. 


\section{Literature Review}

\subsection{Attachment Theory}

According to the attachment theory Bowlby $(1969,1973,1982)$ the attachment that forms between an infant and a caregiver is important for the infant's survival. Secure attachment forms if the caregiver is responsive to the infant's needs especially when the infant is in distress. A caregiver who is caring and available fosters secure attachment. Insecure attachment results from a caregiver who is unresponsive, uncaring and unavailable to comfort the infant and provide for his or her needs. Bowlby stated that the attachment relationships formed in early life are ingrained in an individual in the form of internal working models. Internal working models consist of a "selfimage" which is how the infant perceives him or herself and an "other image" which is how the infant perceives the caregiver. The child with secure attachment has a self-image in which he or she is good, lovable and deserving of the caregivers' love and care. The child views the attachment figure as reliable, available and trustworthy. The infant with secure attachment is comfortable approaching the caregiver when in need and readily explores the environment with the caregiver serving as a secure base. Infants with insecure attachment have a different way of interacting with caregivers depending on how they perceive the caregiver.

Ainsworth, Blehar, Waters, and Wall (1978) explained that children with ambivalent attachment employ a hyperactivating strategy designed to draw the caregivers' attention. Such infants worry about abandonment and constantly seek the caregiver's attention usually through heightened negative emotions. On the other hand, infants with avoidant attachment employed a deactivating strategy. These are infants who, from experience, learn that attempts to get attention from caregivers will be ignored or met with hostility. They therefore become emotionally independent and conceal their emotions. Children with disorganized attachment as described by Main and Solomon (1986) did not exclusively rely on a hyperactivating or deactivating strategy in their relationship with caregivers. They may show hostility to caregivers while also demanding caregivers' attentions.

The internal working models of early attachment relationships are stable throughout a person's life and determine attachment styles later in life (Bartholomew \& Horowitz, 1991). Mikulincer and Shaver (2012), described insecure attachment in terms of attachment anxiety and attachment avoidance. People with preoccupied attachment style have high levels of attachment anxiety and are similar to the infant with ambivalent attachment. In relationships with attachment figures, they tend to use a hyperactivating strategy. People with dismissing attachment style have high level of attachment avoidance and rely on a deactivating strategy in relationships with attachment figures and are similar to avoidant infants. People with fearful attachment have high levels of attachment anxiety and avoidance.

By adolescence, parents are still important primary attachment figures but other people, including peers, friends, romantic partners and teachers, may play the role of secondary attachment figures. Adolescents have an attachment style which influences their attachment relationships with primary and secondary attachment figures and should be viewed more as an individual trait than a way of associating with any particular person (Allen, 2008). Attachment security plays an important role in adolescents' mental wellbeing, emotional regulation, interpersonal relationships and may influence involvement in deviant behaviors such as substance use.

\subsection{Attachment Styles and Substance Use}

Attachment security is an important determinant of how people regulate their emotions, thoughts and behaviors (Allen, 2008). Researchers have argued that substance use might be linked to difficulty with emotional regulation (Chassin, Sher, Husson \& Curran, 2013). Schindler (2019) maintains that individuals with insecure attachment have difficulty regulating their emotions and coping with distress. This is because people with insecure attachment lack close, trustworthy relationships they can turn to for comfort when they are facing challenges. Moreover, he notes that people with insecure attachment find forming and maintaining supporting relationships difficult because they have a negative view of other people so they have few people they could turn to when they face challenges. Consequently, a person with insecure attachment can take alcohol or other psychotropic substances as a form of "self-medication" that helps to relieve stress. Individuals with insecure attachment may attempt to fill in the missing bonds with alcohol and other drugs (Schindler \& Broning, 2015).

Individuals with insecure attachment styles have negative feelings about themselves because they developed negative self-schema as a result of their relationship with caregivers who did not value and nurture them (Fairbairn et al, 2018). This may play a role in deviant behavior such as substance use. In a longitudinal study, Lockhart and colleagues (2017) investigated whether African American adolescents' self-worth mediated the link between attachment and deviant behavior. The authors reported that attachment security predicted self-worth one 
year later and self-worth predicted less involvement in violence, weapon possession and substance use three years later. The authors came to the conclusion that adolescents with insecure attachment had low self-worth which made them devalue themselves and because they devalued themselves, they did not care so much about their personal wellbeing and did not desist from harmful behavior like substance use.

Kassel, Wardle and Roberts (2007) concluded that insecure attachment, more so anxious attachment, predicted not only the frequency of substance use but also the tendency to use substances in response to stress. In their study that involved college students, the authors noted that individuals with insecure attachment styles also had negative attitudes towards themselves as well as low self-esteem. Whenever such individuals are stressed or their self-esteem is threatened, they use substances to relieve the stress and reduce their negative emotions. Echoing Kassel and colleagues (2007), Levitt and Leonard (2015) found a greater tendency of using alcohol as a coping mechanism among individuals with insecure attachment. They found that attachment anxiety, and to a lesser extent attachment avoidance, predicted drinking to cope with emotions among married couples. Moreover, Molnar, Sadava, DeCourville and Perrier (2010) have found that people with high levels of attachment anxiety are more likely to misuse alcohol if they drink to cope with their emotions.

Insecure attachment styles have been found to predict substance use in empirical studies. In a study involving Lebanese adolescents, Nakhoul and colleagues (2020) found that addiction was significantly predicted by both attachment anxiety and attachment avoidance. This study showed that adolescents who had preoccupied, dismissing and fearful attachment styles were significantly more likely to be addicted to alcohol, cigarettes and water pipe whereas those with secure attachment style were not. Hayre, Goulter and Moretti (2019) explored associations between maltreatment in childhood, attachment and substance use in a sample of 12- to 18-year-old adolescents. Attachment avoidance significantly predicted frequency of alcohol use, cigarette smoking, marijuana use and use of other drugs but attachment anxiety did not. Moreover, attachment avoidance mediated the link between psychological maltreatment during childhood and alcohol use and cigarette smoking among the adolescents. Adroom, Mirlotfi, Nikmanesh, Shahidi and Keikha (2014) found that attachment anxiety but not avoidance predicted tendency to use drugs in 19- to 24-year-old college students. Thus, it may seem that in some situations, attachment anxiety or avoidance may play different roles in regards to predicting substance use. Pooravari, Ghanbari, Mohammadi, Panaghi and Aghdasta (2014) found that substance use was related to attachment in 18- to 30-year-old adults. When they compared respondents with secure attachment and to those with insecure attachment, respondents with insecure attachment were more likely to have smoked, taken alcohol or used other substances.

Schindler and Broning (2015) have suggested that adolescents will, regardless of their attachment, typically experiment with psychoactive substances but those with insecure attachment end up developing problematic substance use habits. Cömert and Ögel (2014) found, however, that attachment security may also predict adolescents who will experiment with psychoactive substances. In their study where they explored attachment styles and substance use among adolescents, they found that adolescents with preoccupied and dismissing attachment styles were significantly more likely to have experimented with intoxicating substances. This finding shows that attachment anxiety and avoidance were predictors of experimentation with substances. The authors also reported that higher levels of attachment anxiety and avoidance predicted use of multiple substances among the adolescents.

Although empirical studies have repeatedly shown that insecure attachment styles are significantly associated with substance use, Musetti, Terrone, Corsano, Magnani and Salvatore (2016) have proposed that substance use has nothing to do with attachment insecurity or attachment styles. Instead, they suggest that all adolescents, including those with secure attachment may consume substances that are acceptable in their cultures. The findings reported by some studies have supported Musetti and colleagues. For example, Estévez and colleagues (2017) explored the effects of attachment and emotional regulation on substance related and nonsubstance related addictive behaviors in 13- to 21-year-old youths. Respondents' attachment to their mothers, fathers or peers was not significantly related to alcohol or drug use but significantly predicted gambling, addiction to video games and problematic internet use. From the existing literature, there is ample evidence that substance use is linked to attachment security but the evidence is not unequivocal.

\section{Methodology}

This study targeted 10,451 Form Three students in public secondary schools in Nairobi County. A correlational research design was adopted for the study. Purposive sampling was used to select three out of the nine sub-counties in Nairobi County. Nine out of 28 schools in the three sub-counties were selected and stratified into: boys only 
schools, girls only schools and mixed schools. Out of each stratum, three schools were randomly selected hence nine schools were included in the study. Simple random sampling was used to select 385 students from the nine schools. The size of the sample was determined using the formula by Yamane (1967):

$$
n=\frac{N}{1+N(e)^{2}}
$$

Where:

$n=$ desired sample

$N=$ total number of Form Three students

$e=$ margin of error at .05

Data for was collected using self-administered questionnaires. Secondary school student's attachment styles were measured using the 24 item Attachment Styles Questionnaire. The ASQ has subscales measuring secure, preoccupied, dismissing and fearful attachment styles. Substance use was measured using a five-point likert scale with 11 items.

\section{Results and Discussion}

The descriptive statistics for the study variables are summarized in Table 1.

Table 1: Descriptive Statistics for Study Variables

\begin{tabular}{llllll}
\hline Study Variables & & Min & Max & Mean & SD \\
\hline Secure Attachment & Male & 7.00 & 35.00 & 22.83 & 5.23 \\
& Female & 7.00 & 35.00 & 23.81 & 5.38 \\
\hline Preoccupied Attachment & Male & 7.00 & 34.00 & 20.54 & 6.65 \\
& Female & 7.00 & 32.00 & 19.44 & 8.31 \\
\hline Dismissing Attachment & Male & 5.00 & 25.00 & 15.81 & 4.79 \\
& Female & 5.00 & 25.00 & 14.88 & 5.75 \\
\hline Fearful Attachment & Male & 5.00 & 25.00 & 16.06 & 4.74 \\
& Female & 5.00 & 25.00 & 15.86 & 5.96 \\
\hline Substance Use & Male & 10.00 & 42.00 & 16.33 & 8.02 \\
& Female & 10.00 & 46.00 & 15.35 & 7.77 \\
\hline
\end{tabular}

Note: Min $=$ minimum Max $=$ Maximum SD $=$ Standard deviation

According to Table 1, girls had a higher mean than boys (23.81 versus 22.83) for secure attachment style. Boys, however, had higher means than girls for preoccupied attachment style (20.54 versus 19.44), dismissing attachment style (15.81 versus 14.88) and fearful attachment style (16.06 versus 15.86). The differences in the means imply that on average, boys were more likely to have insecure attachment styles compared to girls. In regards to substance use, boys had a higher mean than girls (16.33 versus 15.35). The bivariate correlations between substance use and attachment styles are presented in Table 2. 
Table 2: Correlations between Attachment Styles and Substance Use

\begin{tabular}{ll}
\hline Attachment Styles & Substance Use \\
\hline Secure Attachment & $-.125^{*}$ \\
Preoccupied Attachment & $.119^{*}$ \\
Dismissing Attachment & $.176^{* *}$ \\
Fearful Attachment & -.008 \\
\hline
\end{tabular}

Note: $* \mathrm{P}<.05 * * \mathrm{P}<.01$

As shown in Table 2, a negative and statistically significant correlation was found between secure attachment and substance use $(\mathrm{r}=-.125, \mathrm{P}=.010)$ which implies an inverse relationship between substance use and secure attachment. Positive and statistically significant correlations were observed between substance use and preoccupied attachment $(\mathrm{r}=.119, \mathrm{P}=.013)$ as well as dismissing attachment $(\mathrm{r}=.176, \mathrm{P}=.001)$. These findings imply that higher levels of preoccupied and dismissing attachment were associated with more substance use. The correlation between substance use and fearful attachment was weak and not statistically significant $((\mathrm{r}=-.008, \mathrm{P}$ $=.44$ ) implying that fearful attachment was not associated with substance use. It is clear from these findings that attachment styles influenced substance use among secondary school students. The researcher carried out multiple linear regression analysis to determine the predictive weight of the attachment styles and to test the study hypothesis. Analysis of variance (ANOVA) was used to test the fitness of the regression model at the .05 level of significance. The ANOVA is summarized in Table 3.

Table 3: ANOVA for Substance Use

\begin{tabular}{|c|c|c|c|c|c|}
\hline Model & $\begin{array}{l}\text { Sum } \\
\text { Squares }\end{array}$ & $\mathrm{df}$ & Mean Square & $\mathrm{F}$ & Sig. \\
\hline Regression & 1179.577 & 4 & 294.894 & 4.954 & .001 \\
\hline Residual & 20058.467 & 337 & 59.521 & & \\
\hline Total & 21238.044 & 341 & & & \\
\hline
\end{tabular}

Dependent Variable: Substance Use

Predictors: (Constant), Fearful Attachment, Secure Attachment, Preoccupied Attachment, Dismissing Attachment

As shown in Table 3, the regression model predicting students' substance use was statistically significant $(\mathrm{F}=4.954, \mathrm{P}=.001)$ which means attachment styles significantly predict substance use among secondary school students in Nairobi County. This finding led to the rejection of the null hypothesis because the regression model could not be attributed to chance only. The regression model is summarized in Table 4

Table 4: Model Summary for Substance Use

\begin{tabular}{llll}
\hline $\mathrm{R}$ & R Square & Adjusted R Square & $\begin{array}{l}\text { Std. Error of the } \\
\text { Estimate }\end{array}$ \\
\hline .236 & .056 & .044 & 7.71496
\end{tabular}

Predictors: (Constant), Fearful Attachment, Secure Attachment, Preoccupied Attachment, Dismissing Attachment Dependent Variable: Substance Use

The model summary presented in Table 4 shows that attachment styles explained $5.6 \%$ of the variance in students' substance use $\left(\mathrm{R}^{2}=0.56\right)$. The model's regression coefficients are presented in Table 5 . 
Table 5: Regression Coefficients for Substance Use

\begin{tabular}{llllll}
\hline & \multicolumn{2}{l}{$\begin{array}{l}\text { Unstandardized } \\
\text { Coefficients }\end{array}$} & $\begin{array}{l}\text { Standardized } \\
\text { Coefficients }\end{array}$ & $\mathrm{t}$ & Sig. \\
\cline { 2 - 7 } & $\mathrm{B}$ & Std. Error & Beta & & \\
\hline (Constant) & 16.560 & 2.498 & & 6.630 & .000 \\
Secure Attachment & -.173 & .079 & -.117 & -2.205 & .028 \\
Preoccupied Attachment & .083 & .062 & .080 & 1.342 & .180 \\
Dismissing Attachment & .258 & .088 & .174 & 2.925 & .004 \\
Fearful Attachment & -.145 & .085 & -.100 & -1.709 & .088 \\
\hline
\end{tabular}

Dependent Variable: Substance Use

According to Table 5, secure attachment style was a statistically significant predictor of students' substance use. The negative and statistically significant regression coefficient $(\beta=-.117, \mathrm{P}=.028)$ implies that the more securely attached a student was, the less his or her likelihood of using substances was. The positive and statistically significant regression coefficient for dismissing attachment style $(\beta=.174, \mathrm{P}=.004)$ shows that dismissing attachment was also a significant predictor of students' substance use but in the opposite direction from secure attachment style. Having a dismissing attachment style predicted higher likelihood of substance use.

The regression coefficient for preoccupied attachment was small and not statistically significant $(\beta=$ $-.080, \mathrm{P}=.180$ ). Therefore, although preoccupied attachment was significantly correlated with substance use, it had less predictive power than secure and dismissing attachment styles in the regression analysis. Finally, fearful attachment style, which was not significantly correlated with substance use, had a negative but not statistically significant regression coefficient $(\beta=-.100, \mathrm{P}=.088)$ therefore it was not a significant predictor of students' substance use.

This study investigated whether secondary school students' attachment styles predicted substance use behavior. Secure attachment style predicted students' substance use. Secure attachment style was not only negatively correlated with substance use, it also significantly predicted less substance use in the regression analysis. This finding concurs with earlier findings that have associated secure attachment with less involvement is substance use among adolescents (Cömert \& Ögel 2014; Nakhoul et al, 2020). The finding of this study also echoes Borhani (2013) who found that college students exhibiting insecure attachment were more likely to abuse substances compared to those exhibiting secure attachment. In a review of earlier studies that had examined the associations between attachment security and substance use, Schindler and Broning (2015) had found evidence that insecure attachment predicted substance use. Fairbairn and colleagues (2018) also came to the conclusion that secure attachment was protective against substance use after reviewing longitudinal studies with more than 50,000 participants in which individuals with secure attachment were found to be less involved in substance use.

Turning to the insecure attachment styles, preoccupied and dismissing attachment styles were significantly correlated with substance use although in the regression analysis, dismissing attachment style significantly predicted substance use and preoccupied attachment style did not. These findings imply that higher levels of attachment anxiety (preoccupied attachment style) and higher levels of attachment avoidance (dismissing attachment style) were associated with greater propensity to use substances. These findings concur with findings made in earlier studies by Cömert and Ögel (2014) who found that adolescents with dismissing and preoccupied attachment styles were more likely to experiment with substance use and ended up using multiple substances. The findings of this study also support findings in a study by Nakhoul and others (2020) which found that preoccupied and dismissing attachment styles predicted addiction to alcohol, cigarettes and water pipe smoking among Lebanese adolescents. In another study that agrees with this study, Asghari and colleagues found that avoidant attachment and ambivalent/anxious attachment predicted drug abuse among young adults.

The study showed that attachment avoidance was a greater predictor of adolescents' substance use than attachment anxiety. This finding is in line with the finding by Hayre and colleagues (2019) in which attachment avoidance and not anxiety, predicted drinking, smoking, marijuana and other drug use. However, in the current study, attachment anxiety was significantly correlated with substance use hence it made a smaller contribution to students' substance use. The fearful attachment style did not predict substance use in this study, a finding that was unexpected and contradicted the finding by Nakhoul and others (2020) in which fearful attachment was associated with addiction along with preoccupied and dismissing attachment styles. 


\section{Conclusion}

Taken together, this study has established that attachment styles are significant predictors of substance use among secondary school students in Nairobi County. In particular, secure attachment style predicted less substance use. This shows that secondary school students with secure attachment have lower risk of using substances compared to their counterparts who have insecure attachment styles. In regards to the insecure attachment styles, it emerged that dismissing attachment style was the most important predictor of substance use. This implies that students with high levels of attachment avoidance were significantly more likely to use substances compared to those with high levels of attachment anxiety. Overall, the findings in this study failed to support the suggestion made by Musetti and colleagues (2016) that adolescents use substances that are culturally acceptable regardless of their attachment security. This study was done in Nairobi County where various substances are widely available and yet it has demonstrated that propensity to use substances is related to attachment security in the sense that secure attachment style predicted less substance use.

\section{Recommendations}

Substance use among adolescents is a health risk behavior with serious consequences. This study has found that secure attachment style reduces involvement in substance use behavior. It is important therefore to enlighten parents and other caregivers on the importance of fostering secure attachment in their children so that they will have secure attachment style by the time they arrive at secondary school. In school, guidance and counseling teachers may assess students' attachment security and pay closer attention to student with insecure attachment styles as they are at higher risk of indulging in alcohol and other drug use.

\section{References}

Abur, J. O. (2014). Drug and Substance Abuse Among Secondary School Students, in Embakasi District, Nairobi County. Unpublished M.A Thesis, University of Nairobi.

Adroom, M., Mirlotfi, P. R., Nikmanesh, Z., Shahidi, R., \& Keikha, L. (2014). Prediction of Addiction Potential in Youth According to Attachment Styles. Zahedan J Res Med Sci, 16(5), 89-91.

Ainsworth, M.D.S., Blehar, M.C., Waters, E., \& Wall, S. (1978). Patterns of attachment: A psychological study of the strange situation. Hillsdale, NJ: Lawrence Erlbaum.

Allen, J.P (2008) The attachment system in adolescence. In: J. Cassidy \& P.R. Shaver (Eds.), Handbook of attachment: Theory, research, and clinical applications (2nd ed). p. 419-435. New York: Guilford

Asghari, F., Sadeghi, A., Sadati, S. M. R., Entezari, M., \& Saadat, S. (2015). The Relationship between Attachment Styles and Parenting Styles with Tendency to Drug Abuse among University Students. Indian Journal of Fundamental and Applied Life Sciences, 5(s2), 144-149.

Bartholomew, K., \& Horowitz, L. (1991). Attachment styles among young adults: A test of a four-category model. Journal of Personality and Social Psychology, 61, 226-244.

Borhani, Y. (2013). Substance Abuse and Insecure Attachment Styles : A Relational Study. LUX, 2(1)

Bowlby, J. (1969). Attachment and loss: Vol. 1 Attachment. New York: Basic books.

Bowlby, J. (1973). Attachment and loss: Vol. 2. Separation. New York: Basic Books.

Bowlby, J. (1982). Attachment and loss: Vol. 2. Attachment. New York: Basic Books.

Brown, S., A, McGue, M., Maggs, J., et al (2008) A developmental perspective on alcohol and youths 16 to 20 years of age. Pediatrics 21(4): S290-S310

Chassin, L., Sher, K. J., Hussong, A., \& Curran, P. (2013). The developmental psychopathology of alcohol use and alcohol disorders: research achievements and future directions. Development and Psychopathology, 25(4 Pt 2), 1567-84. http://doi.org/10.1017/S0954579413000771.

Cömert, I. T., \& Ögel, K. (2014). Attachment Styles of Adolescent Substance Users. The Turkish Journal on Addictions, 1(1), 26-40. https://doi.org/10.15805/addicta.2014.1.1.001

Copeland WE, Shanahan L, Costello EJ et al (2009) Childhood and adolescent psychiatric disorders as predictors of young adult disorders. Arch Gen Psychiatry 66(7):764-772

Estévez, A. N. A., Jáuregui, P., Sánchez-marcos, I., López-gonzález, H., \& Griffiths, M. D. (2017). Attachment and emotion regulation in substance addictions and behavioral addictions. Journal of Behavioral Addictions, 6(4), 534-544. https://doi.org/10.1556/2006.6.2017.086

Fairbairn, C. E., Briley, D. A., Kang, D., Fraley, R. C., Hankin, B. L., \& Ariss, T. (2018). A Meta-Analysis of Longitudinal Associations between Substance Use and Interpersonal Attachment Security. Psychol Bull, 144(5), 532-555. https://doi.org/10.1037/bul0000141.A

Gore FM, Bloem PJ, Patton GC, et al. (2011) Global burden of disease in young people aged 10-24 years: A 
systematic analysis. Lancet 377(9783): 2093-2102

Hayre, R. S., Goulter, N., \& Moretti, M. M. (2019). Addictive Behaviors Maltreatment, attachment, and substance use in adolescence: Direct and indirect pathways. Addictive Behaviors, 90, 196-203. https://doi.org/10.1016/j.addbeh.2018.10.049

Jordan, C.J. \& Andersen, S.L. (2017). Sensitive periods of substance abuse: Early risk for the transition to dependence. Dev. Cogn. Neurosci. 25, 29-44. https://doi.org/10.1016/J.DCN.2016.10.004

Jumbe, S., Mwenda-Kamninga, T., Mwalwimba, I., \& Kalu, U.-G. (2021). Determinants and Effects of Adolescent Substance Use in Africa: A Systematic Review Protocol. Systematic Reviews, 10(125). https://doi.org/10.21203/rs.3.rs-37924/v1

Kamenderi, M., Muteti, J., Okioma, V., Nyamongo, I., Kimani, S., Kanana, F., \& Kahiu, C. (2019). Status of Drugs and Substance Use among Secondary School Students in Kenya. African Journal of Alcohol \& Drug Abuse, Edition 1.

Kassel, J. D., Wardle, M., \& Roberts, J. E. (2007). Adult attachment security and college student substance use. Addictive Behaviors, 32, 1164-1176. https://doi.org/10.1016/j.addbeh.2006.08.005

Kingendo, M. (2015). Behaviour Disorders Related to Drug Abuse Among Secondary School Students in Kenya. Journal of Education and Practice, 6(19), 170-179.

Kisilu, J., Ayuya, S., Ndolo, J., \& Mwavua, S. (2019). Prevalence And Patterns Of Early Drug Abuse Among Clients Attending Ngara Medically Assisted Therapy Clinic Nairobi , Kenya - A Retrospective Study. African Journal of Alcohol \& Drug Abuse, Edition 1, 28-34.

Kulak, J. A., \& Griswold, K. S. (2019). Adolescent Substance Use and Misuse : Recognition and Management. American Family Physician, 99(11), 689-696.

Lee, A., \& Hankin, B. L. (2009). Insecure Attachment, Dysfunctional Attitudes, and Low Self- Esteem Predicting Prospective Symptoms of Depression and Anxiety During Adolescence. J Clin Child Adolesc Psychol, 38(2), 219-231. https://doi.org/10.1080/15374410802698396.

Levitt, A., \& Leonard, K. E. (2015). Insecure Attachment Styles, Relationship-Drinking Contexts, and Marital Alcohol Problems: Testing the Mediating Role of Relationship-Specific Drinking-to-Cope Motives. Psychol Addict Behav, 29(3), 696-705. https://doi.org/10.1037/adb0000064.Insecure

Lockhart, G., Phillips, S., Bolland, A., Delgado, M., Tietjen, J., \& Bolland, J. (2017). Prospective Relations among Low-Income African American Adolescents' Maternal Attachment Security, Self-Worth , and Risk Behaviors. Front Psychol, 8(33). https://doi.org/10.3389/fpsyg.2017.00033

Main, M., \& Solomon, J. (1986). Discovery of an insecure, disorganized / disoriented attachment pattern: Procedures, findings, and implications for the classification of behavior. In M. Yogman \& T. B. Brazelton (Eds.), Affective development in infancy (pp. 95-124). Norwood, NJ: Ablex.

Mikulincer, M., \& Shaver, P. R. (2012). An attachment perspective on psychopathology. World Psychiatry, 11, 11-15.

Milin, R., \& Walker, S. (2015). Adolescent and Substance Abuse. In N. El-Guebaly (Ed.), Textbook of Addiction Treatment: International Perspectives (Issue January 2015, pp. 2220-). Springer. https://doi.org/10.1007/978-88-470-5322-9

Molnar, D. S., Sadava, S.W., De Courville, N. H., \& Perrier, P. K. (2010). Attachment, Motivations, and Alcohol: Testing a Dual-Path Model of High-Risk Drinking and Adverse Consequences in Transitional Clinical and Student Samples. Canadian Journal of Behavioural Science/Revue canadienne des sciences du comportement, 42 (1): 1-13. DOI: 10.1037/a0016759.

Mulvey, E. P., Schubert, C. A., \& Chassin, L. (2010). Substance Use and Delinquent Behavior Among Serious Adolescent Offenders (Issue December).

Musetti, A., Terrone, G., Corsano, P., Magnani, B., \& Salvatore, S. (2016). Exploring the Link among State of Mind Concerning Childhood Attachment, Attachment in Close Relationships, Parental Bonding, and Psychopathological Symptoms in Substance Users. Front Psychol, 7(1193). https://doi.org/10.3389/fpsyg.2016.01193

NACADA. (2010). Alcohol Use in Central Province of Kenya: A Baseline Survey on Magnitude, Causes and Effects from the Perspective of Community Members and Individual Users. Nairobi: Government Printer

NACADA (2012). A National Survey on the Magnitude of Alcohol and Drug abuse in Kenya Nairobi: Government Printer Nairobi

NACADA (2016). Report on National ADA Survey among Secondary School Students. Nairobi: Government Printer Nairobi

Nakhoul, L., Obeid, S., Sacre, H., Haddad, C., Soufia, M., Hallit, R., ... Hallit, S. (2020). Attachment style and addictions (alcohol, cigarette, waterpipe and internet) among Lebanese adolescents: a national study. BMC Psychology, 8(33).

Njoki, K. M. (2013). Drug And Substance Abuse In Secondary Schools In Kenya. A Case Study of Kiambu County. Unpublished M.Ed Thesis, University of Nairobi. 
Olawole-Isaac, A., Ogundipe, O., Amoo, E. O., \& Adeloye, D. (2018). Substance use among adolescents in subSaharan Africa: A systematic review and meta-analysis. SAJCH South African Journal of Child Health, 12(Special Issue), S79-S84. https://doi.org/10.7196/SAJCH.2018.v12i2.1524

Omboto, J. O., Ondiek, G. O., Odera, O., \& Ayugi, M. E. (2012). Factors Influencing Youth Crime and Juvenile Delinquency. International Journal of Research In Social Sciences, 1(2), 18-21.

Ondieki, A. G. (2017). Preventive Measures to Drug Abuse in Secondary Schools. Eldoret, Kenya: Utafiti Foundation.

Owino, J. (2017). Awareness and Knowledge of Drug and Substance Use among 18-24 Year-Old Female Adolescents: A Case Study of Soweto - Kayole Nairobi County. Unpublished MA Thesis, University of Nairobi.

Pooravari, M., Ghanbari, S., Mohammadi, A. Z., Panaghi, L., \& Aghdasta, E. (2014). The Comparison of Tendency to Risky Behaviour, in Secure/Insecure Attachment in Parents. International Journal of Scientific Research and Innovative Technology, 1(1), 11-25.

Schindler, A. (2019). Attachment and Substance Use Disorders - Theoretical Models , Empirical Evidence , and Implications for Treatment. Front. Psychiatry, 10(727). https://doi.org/10.3389/fpsyt.2019.00727

Schindler, A., \& Broning, S. (2015). A Review on Attachment and Adolescent Substance Abuse: Empirical Evidence and Implications for Prevention and Treatment. Substance Abuse, 36(3), 304-313. https://doi.org/10.1080/08897077.2014.983586

Schulte, M.T. \& Hser, Y.I. (2014). Substance Use and Associated Health Conditions throughout the Lifespan. Public Health Rev. 35

Waithima, C. (2017). Substance Use Assessment among School Going Adolescents in Kenya. African Journal of Clinical Psychology, 1, 23-35.

Yamane, T. (1967) Statistics: An introductory analysis (2nd ed). New York: Harper \& Row. 